\title{
Exploring downsizing: a case study of airline company of Pakistan
}

\author{
Shahbaz Hussain ${ }^{1 *}$, Hafiza Hafsa Nayyab ${ }^{1}$, Zeeshan Fareed ${ }^{2}$, Haseeb Ahmad ${ }^{1}$, Farrukh Shahzad ${ }^{3}$ \\ ${ }^{1}$ Department of Business Administration, University of Education, Lahore (Multan/Okara Campus), Pakistan \\ ${ }^{2}$ Department of Management Sciences, COMSATS Institute of Information Technology Sahiwal, Pakistan \\ ${ }^{3}$ Department of Business Administration, Lahore Leads University, Lahore, Pakistan \\ *Corresponding author E-mail: rai_shahbaz_hussain@ue.edu.pk
}

\begin{abstract}
Pakistan is facing economic downfall for the past few years and this has created adverse impact on all government and private organizations. Due to economic downfall organizations are reducing number of employees to decrease their costs by using downsizing. This study investigated the consequences of downsizing on survivor employees in a leading airline company of Pakistan. Case study technique has been used and data has been collected through un-structured interviews from 12 employees. NVivo 10 software has been applied for in-depth qualitative analysis. Different techniques have been used for the validation of different themes of the study including graphs, word tag clouds, word tree map and tree map. The findings depicted 14 more or less critical consequences of downsizing on survivor employees. More critical consequences are perceptions about work, internal feelings, internal motivation, job satisfaction, organizational commitment, career development, employee performance, feelings of job insecurity, thinking for better opportunity and stress. Less critical consequences are increase in workload, fear of job loss, bad health and thinking to switch. These consequences of downsizing can be divided into two major categories such as effects on attitudes and effects on behaviors. It is concluded that employees with less experience are more inversely affected by downsizing. Downsizing has negatively affected attitudes and behaviors of survivor employees in leading Airline Company of Pakistan but impact on attitudes is higher than on behaviors.
\end{abstract}

Keywords: Attitudes, Behaviors, Downsizing, Survivors, NVivo.

\section{Introduction}

During past several years economic conditions of the world have put organizations into severe financial stress. Organizations are using various means to reduce cost and to enhance chances of their survival in these bad financial times. Majority of cost cutting strategies lead to reduction in human resources of the organization by using downsizing or rightsizing. These two approaches are often confused with each other. Downsizing means reduction in workforce size and rightsizing is associated with maintaining a balance between work and its staffing requirements. Downsizing is often associated to external factors such as bad economic conditions whereas rightsizing is used in majority of the cases where the organization is either restructuring or reorganizing its business operations to improve efficiency and reduce costs. Downsizing and its consequences have been comprehensively recognized during 1980's when large number of businesses applied this approach to reduce their staff. During these times collected works described that to respond crisis situations organizations extensively decrease their workforce as a mean of reducing labor costs. This quick response approach indicated a narrow and short-term focus on reducing immediate costs.

But it has been evidenced that some successful organizations also reduce its workforce for enhancing business effectiveness. This has given emergence to the approach of rightsizing but researchers of this time considered rightsizing as a form of downsizing. This phenomenon is more intense in developing or third world coun tries because these are facing economic recession intensely. Pakistan is badly facing economic downfall for the last few years and rate of unemployment is also increasing. Energy crisis and high rate of inflation has increased cost of business operations in Pakistan. Despite of creating new job opportunities to accommodate a large labor pool, previous job opportunities are also diminishing. So the present study will be of great significance as it will provide a better insight of the phenomenon in context of Pakistan.

The intent of the present study is to explore consequences of downsizing on survivor employees in Pakistan. This study is qualitative in nature and case study method will be used to explore the phenomena. Data will be collected by using semi-structured interviews and sample will be chosen by using convenience sampling approach. For data analysis NVivo 10 software will be used and many qualitative data analysis techniques such as graphs word tree map, word tag clouds and tree map will be applied to enhance validity of data. Results will be interpreted and conclusions will be drawn on the basis of findings.

\section{Literature review}

Researchers described downsizing from three different perspectives across history. First view point came into existence when researchers defined downsizing as a way of responding quickly to bad economic conditions. It resulted in survivor's stress, more workload problems and job security issues (Bennett 1991; Lublin 1991; Baumohl 1993; Pearlstein 1994). Organizations focus 
mainly on cost reduction when facing losses and use downsizing to reduce excessive labor cost as identified by (Harrigan 1980a 1980b). In this era researchers confined their work only at finding out instant responses of the organizations, the downsized workforce and survivors (Greenhalgh \& Rosenblatt 1984; Perry 1986; Brockner 1988; Leana \& Feldman 1992). It has also been identified by Cascio (1998) that downsizing is mainly done to cut cost. Second category of researchers presented another perspective of downsizing. These researchers described that numerous effective organizations proactively reduced their workforce not because of as a quick response to immediate financial crisis but as a part of their revamping and restructuring business operations strategy. Stationary profits were the main reason behind being so proactive (Hoerr 1988; Cameron 1994; Feldmen \& Leana 1994). Different organizations have different policies of downsizing, some downsize due to losses while others reduce their workforce to enhance profits. Organizations vary in terms of the way they adopt downsizing. Researchers directed efforts on exploring the way organizations declare and apply downsizing as indicated by (Schweiger, et al., 1987). Some identified the process of providing support and guidance to employees being downsized (Cameron, et al., 1991) while others devised the counseling strategies for employees after downsizing as a way of assisting in finding new jobs or careers such as work done by (Leana \& Feldman, 1992). Remaining found the consequences of downsizing on survivors in terms of their health, anger and depression and also provided suggestions to reduce these after effects of downsizing on survivors (Greenhaulgh \& Jick, 1989).

Third type of researchers is also divided into further two categories: Macro oriented researchers and micro oriented researcher Macro oriented researchers are from strategic management and organizational theory field whereas micro oriented researchers are organizational behavior and human resource specialists. Macro oriented researchers identified the broader external influences that pressurize organizations to downsize and these researchers mainly focused on antecedents of downsizing. Which factors mainly sets an organization on the path of downsizing? Major contributions in this field are of Freeman \& Hannan (1975), Hambrick \& D'Aveni (1988) and Kimberly \& Miles (1980).

Second category micro researchers are further divided in two groups. First group found the monetary consequences of downsizing. Researchers belonging to this group including Cascio 1998 Clark \& Koonce (1995), DeMeuse, et al. (1997) and Worrall, et al. (2000) directed their efforts to find whether downsizing plays effective role in reducing costs and improving economic condition or not? Most of these researchers concluded that despite of financially reviving the organization, downsizing has more adverse consequences on financial position of the organizations in the long run. It is somehow effective in fulfilling immediate short-term need of cost reduction but in the long-run it does not play a vital role. Other researchers group such as Cook and Ferris (1986), Markham \& McKee (1991) and Mone (1994) found the consequences of downsizing on survivors in terms of their decreased job performance and perceptions about work. These researchers found that due to downsizing survivors face high morale problems that negatively affects their performance. Yu \& Park (2003) devised "survivor's syndrome" which means negative attitudes of survivors towards organization and work environment after downsizing. A few researchers including Cameron, et al. (1987), Schuler \& Jackson (1987) and staw, et al. (1981) investigated both antecedents and consequences of downsizing. These researchers looked at downsizing from both broader and narrower sides, examined broader external influences on downsizing as well as its narrower consequences on individual survivors. These researchers concluded that organizations downsize due to many external factors such as country rules and regulations, bad economic conditions, sense of competition and etc. and when an organization downsizes this affects both organizational and individual performance.

Researchers have identified impact of downsizing on survivors' syndrome. Al-Kazemi \& Zajac (1998) stated that reduction in workforce adversely affects employee's thinking and their actions.
Lam \& Reshef (1999) identified that downsizing negatively disturbs teamwork and employee empowerment. It can convert survivor's positive feelings into negative ones. Armstrong-Stassen (1997) described impact of downsizing on organizational commitment while Sverke, et al. (2002) identified its effect on job security. Downsizing also unfavorably affects employee morale, job satisfaction, absenteeism and turnover.

Researchers who belong post 2000 era investigated the extent and degree of downsizing but there is no consensus over the phenomenon. Williams (2004) and Sronce \& McKinley (2006) stated 3\%$30 \%$ magnitude of downsizing. In the study of Armstrong-Stassen, et al. (2005) it has been concluded that extent of downsizing is related to survivor's syndrome. Greater the size of downsizing the more adverse impacts will be on employee perceptions or it can be said that size of downsizing determines magnitude of survivors' syndrome.

\section{Background of the research}

A study conducted by Saif, et al. (2013) investigated the impact of downsizing on socio-economic condition on affected employees in Airline Company of Pakistan but this has been done with a different perspective. It was quantitative in nature, data was collected with the help of questionnaires and data analysis software that was implied in study was SPSS. The present study is different from prior studies in terms of its methodology e.g. data collection methods, data analysis methods as well as the results. It focuses on exploring consequences of downsizing on survivors in a leading airline company.

\section{Research questions}

This study will focus on exploring answers of the following major research questions:

- What is downsizing and what are its consequences on employees (survivors)?

- What are different consequences of downsizing on employee (survivors) behavior?

- What are different consequences of downsizing on employee (survivors) attitudes?

- What are different recommendations for practitioners responsible for the implementation of downsizing?

\section{Research objectives}

The objectives of study are to explore:

- Consequences of downsizing on behavior of employees in terms of job performance, workload, absenteeism, job security and workload

- Consequences of downsizing on attitudes of employees in terms of organizational commitment, job satisfaction, employee morale, perceptions about work and job stress

- To provide recommendations to practitioners responsible for the implementation of downsizing

\section{Conceptual model}

Figure 1 shows conceptual model. This model shows that downsizing has two major types of consequences on survivor employees. It affects job satisfaction, employee morale, organizational commitment, perceptions about work and creates job stress. It also effects on workload, performance, job security, absenteeism and turnover of survivor employees. 


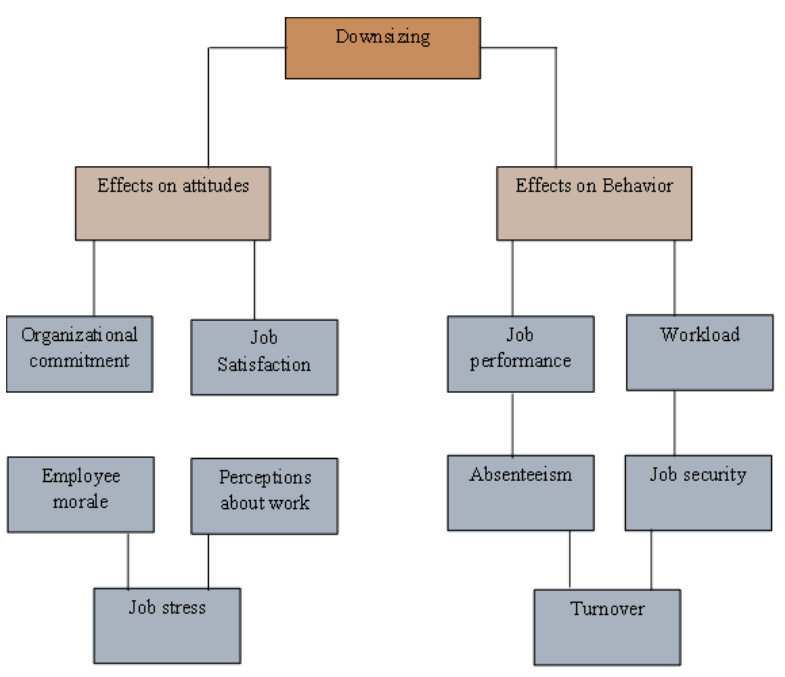

Fig. 1: Conceptual Model

\section{Methodology}

Methodology explains the process of research of research implied in the study. It includes background of the case study, sampling procedure, data collection and analysis method. The upcoming section will cover entire aspects of methodology.

\subsection{Background of case study}

This research uses case study method given by Yin (2003) to explore the phenomenon. Unit of analysis selected are employees of a leading airline company of Pakistan. This company was formed in 1951 and it acquired different airplanes and also expanded its services in many territories of the world. Due to this expansion policy and some external influences, this company continued to hire a large bulk of human resources every year. Now situation is that there are excess employees as compared to assigned job duties Financial position of this organization is very poor and it is facing losses for the last few years. In addition global recession has also adversely affected its business operations. So in order to reduce its labor cost, as a part of overall cost reduction strategy, this organization decided to downsize its excess labor. This organization is currently implementing its first phase of downsizing in its international business operations. This situation has created uncertainty for survivor employees. So there is a strong need to explore the consequences of downsizing on survivor employees and that's why this organization has been selected for case study.

\subsection{Sampling procedure}

Unit of analysis are the employees working in leading Airline Company of Pakistan. Sample of 12 respondents have been selected using non probability convenience sampling approach. This technique is used because it is suitable in case of qualitative research to get in depth data.

\subsection{Data collection method}

Data has been collected from 12 respondents with the help of unstructured interviews. This interviewing technique turned helpful in exploring the consequences of downsizing on survivor's attitudes and behaviors. They have openly expressed what they think and how they feel about downsizing.

\subsection{Data analysis method}

Data has been analyzed by using NVivo 10 software which is specifically designed to manage and analyze qualitative data. This software is very helpful in qualitative data management as Ozkan
(2004) has identified. Researchers of current time are using NVivo software for qualitative data analysis. Lodhi \& Malik (2013) have used Nvivo 10 software to explore impact of load shedding on daily routines in Pakistan. So use of NVivo software is quite appropriate in this paper. Various NVivo data analysis techniques have been applied such as graphs, word tree map, word tag clouds and tree map. These different techniques are used to enhance the validity of results. The upcoming section includes description of techniques applied and findings.

\section{Results \& discussion}

\subsection{Respondent's characteristics}

Three major attributes are associated to respondents: gender, age group and experience. Figure 2 represents that $58.33 \%$ of the respondents are male and $41.67 \%$ are female respondents.

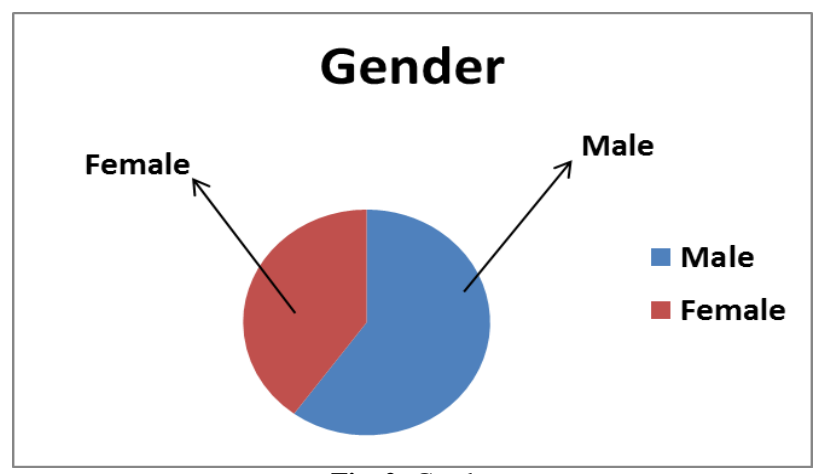

Fig. 2: Gender

Figure 3 represents that respondents belong to different age groups $41.67 \%$ respondents are between the age group 20-30, $16.67 \%$ respondents are between $30-40$ age group and remaining $41.67 \%$ respondents are between 40-50 age group.

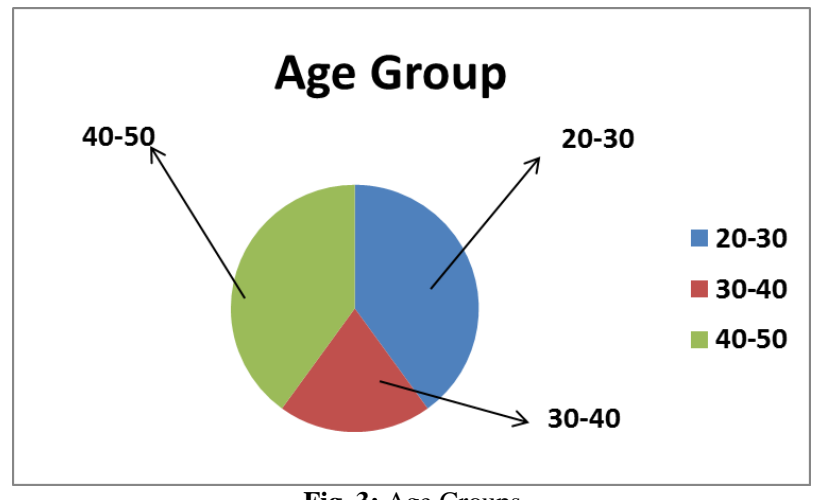

Fig. 3: Age Groups

Figure 4 represents that different respondents have different years of work experience. $41.67 \%$ respondents have less than 5 years of experience, $16.67 \%$ respondents have $10-15$ years of work experience and $41.67 \%$ respondents have more than 15 years of experience. 


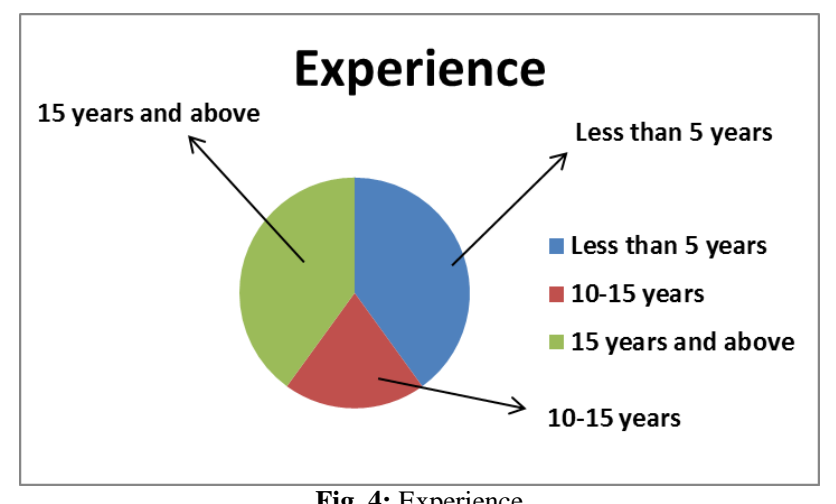

Fig. 4: Experience

\subsection{Word tag cloud}

Word Tag cloud is mostly used in thematic analysis. It identifies variety of themes which are most repeatedly occurring. Size of theme varies according to its frequency. So the theme that has highest frequency will be larger in size than others. It is found under word frequency query in NVivo. Figure 5 represents Word Tag Cloud after funnelling for this study. It shows that that the most repeated theme in this study is downsizing. Other themes that are appearing repeatedly are organization, employees, performance, commitment, stress, thinking, perceptions, motivation, opportunity, environment and career as highlighted in the figure. About affected after all also always any attached attention bad before being best better burden career changed committed company considered contractual cost cut cutting day department despite do don't downsized downsizing emotionally employee employees enhance enjoy environment extent family feel feeling feelings felt from get go good government healthy here hired hiring implemented job know level many more motivated much must need never now number off one opportunity organization other perceptions performance possible reduce right same satisfied say should some sometime soon staff stress think thinking thought threat towards up very wants way well when work working workload.

\section{about affected after all also always}

any attached attention bad before being best

better burden career changed committed company considered contractual cost cut cutting day department despite do don't downsized

\section{downsiz-}

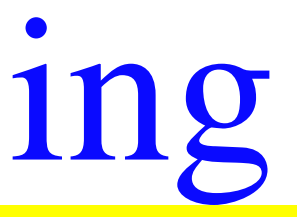

emotionally employee

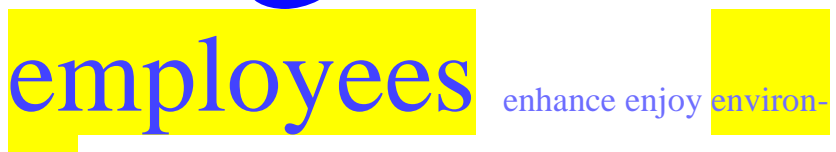
mene extent tamily feel

feeling feelings felt from get go good government healthy here hired hiring

$$
\text { implemented } \mathbf{1} \mathbf{O} \mathbf{b} \text { know level many }
$$

more motivated Much must need never

\section{nOW number off one opportunity 01} ganization

other perceptions

performance possible reduce right same sat-

isfied say should $\mathrm{SOM}$ sometime soon staff stress think thinking thought threat towards up very wants way well When work working
workload

Fig. 5: Word Tag Cloud

\subsection{Word tree map}

Word Tree Map appears in text search query in NVivo. This technique displays the relation of different conversations with a central word. Figure 6 shows word tree map. In this study the central word is downsizing so word Tree Map shows relations of different discussions with the word downsizing.

\subsection{Consequences of downsizing-tree map}

Figure 7 demonstrates Tree Map that identifies the level of various consequences of downsizing on survivor employees. Figure 7 shows more critical and less critical consequences of downsizing on survivor employees. More critical consequences are change in perceptions about work, feelings of job insecurity, impacts on internal feelings, internal motivation, job satisfaction, organizational commitment, thinking for better opportunity, career development, and stress and employee performance. Less critical consequences are increase in workload, fear of job loss, bad health and thinking to switch. Criticality of consequences depends on the frequency of responses. As more respondents give similar answers that factor is considered as more critical such as perceptions about work and feelings of job insecurity have been identified as the most critical factors. 


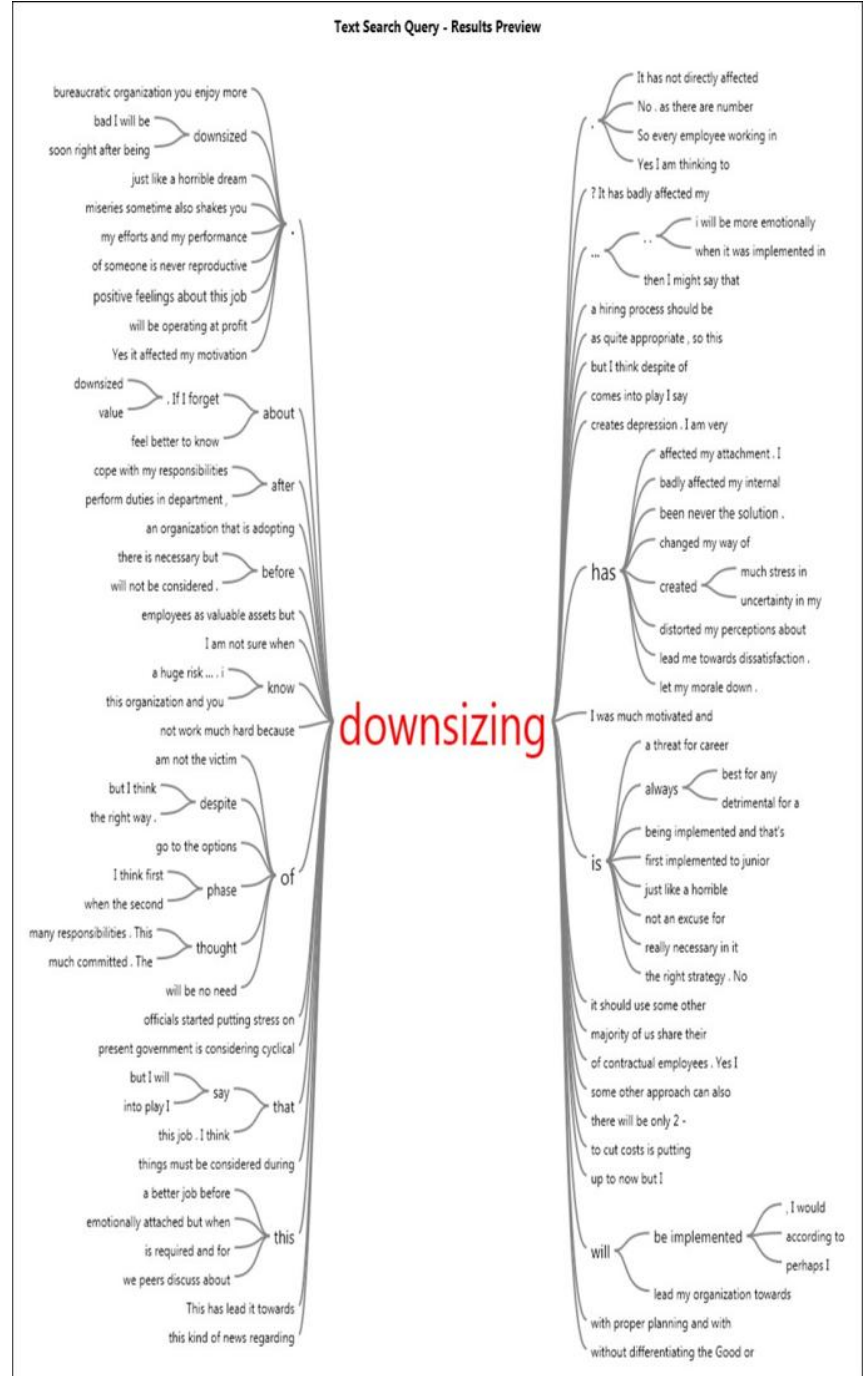

Fig. 6: Word Tree Map

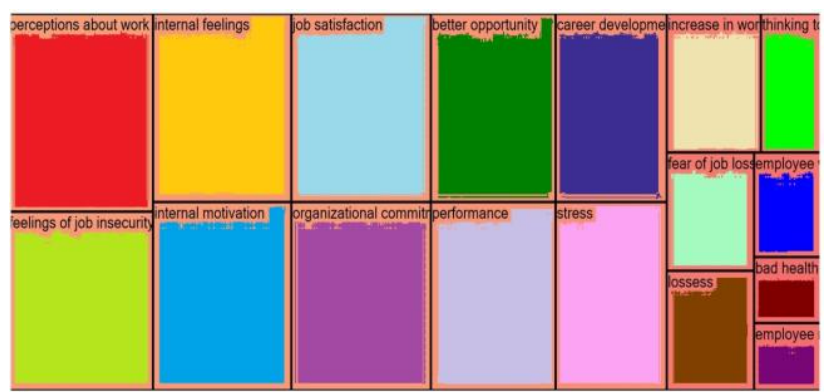

Fig. 7: Tree Map: Extent of Relationship

\subsection{Relation between prior findings and results of cur- rent study}

The effects of downsizing can be divided into two categories: attitudes and behaviors. Yu \& Park (2003) devised "survivor's syndrome" which means negative attitudes of survivors towards organization and work environment after downsizing. Some of these relationships have been identified in literature and others have been explored through the responses of different respondents in the study.

\subsubsection{Downsizing and perceptions about work and perfor- mance}

Cook and Ferris (1986), Markham \& McKee (1991) and Mone (1994) found impacts of downsizing on survivors perceptions about work and employee performance. It has been explored that perceptions about work is the most critical consequence of downsizing. Performance has also been identified as a more critical consequence of downsizing. One of the respondents said that: "I feel I should not work much hard because downsizing will be implemented according to seniority and job performance will not be considered". R2

Other stated that:

"The thought of downsizing has badly affected my internal motivation, commitment and morale. I don't pay more attention to my daily work because I think it will not be rewarded in a better way"R4.

Another said that

"It has not directly affected my level of performance but yes indirect effects are possible because I am not much attentive now as I was before". R8

\subsubsection{Downsizing and job security}

Sverke, et al. (2002) also identified its effect on job security. Similar findings have also been explored from responses in this study related to job security. It has been explored that downsizing is creating feelings of job insecurity among survivors. Its intensity can be considered by looking at the responses. One of the respondents stated that:

"Every employee working in this organization is not feeling secure because higher authorities and government is implementing cyclical downsizing. I don't know when I be kicked off. There is huge uncertainty". R12

Another respondent said that:

"Being a part of an organization that is adopting downsizing to cut costs is putting your future at stake. So I feel very disappointed because of lack of career development opportunities and less job security". ${ }^{9}$

\subsubsection{Downsizing and stress}

It has been identified that downsizing results in survivor's stress, more workload problems and job security issues (Bennett 1991; Lublin 1991; Baumohl 1993; Pearlstein 1994). Stress has also been identified as critical consequence of downsizing.

For example one of the respondents said that:

"Downsizing has created much stress in my life because I have a family and it is my responsibility to financially support them. If I will be downsized.... what I will do then? How I will support my family? I feel under pressure". ${ }^{6}$

Another respondent said that:

"This thought of downsizing creates stress and depression". R3

Another respondent argued that:

"Downsizing is just like a horrible dream. I am much depressed to know about the downsizing because I have a family to support". R2 So it shows that downsizing is creating stress among survivors.

\subsubsection{Downsizing and health of employees}

Downsizing affects health of survivors as identified by (Greenhaulgh \& Jick, 1989). Similar result has been obtained but it has been recognized from Tree Map that it is a less critical factor. One of the respondents stated that"

"Downsizing has badly affected my health. I am afraid of downsizing and news in media desperate me more. Now days I am suffering from high blood pressure". 1

\subsubsection{Downsizing and employee thinking and feelings}

Al-Kazemi \& Zajac (1998) stated that downsizing adversely affects employee's thinking and their actions. It is true because same results have been explored in this study when majority of the respondents gave the similar responses that:

"I am thinking to switch my job as soon as I get some better job opportunity because I am not sure when downsizing will be implemented perhaps I would be kicked off', ${ }^{\text {R2 }}$ 
"Yes I am thinking to quit but as soon as I get good opportunity, I will jump at once because there is a huge risk". ${ }^{3}$

Lam \& Reshef (1999) identified that downsizing can convert survivor's positive feelings into negative ones. Similar findings have been obtained when one respondent replied that:

"I don't have such positive feelings about this job. Downsizing has leaded me towards dissatisfaction. I have a fear that I will be downsized". ${ }^{2}$

\subsubsection{Downsizing and organizational commitment}

Armstrong-Stassen (1997) described impact of downsizing on organizational commitment. It has been explored by the answers of respondents that:

"I don't feel much attached now and I feel I may quit this job as I will get some better job". R11

So the present study confirms the results of prior studies and also it explores some other consequences of downsizing showed in Tree Map.

\section{Conclusion}

This study explored consequences of downsizing on attitudes and behaviors of survivor employees in a leading airline company of Pakistan. Data has been collected through unstructured interviews from different employees working in Airline Company. NVivo 10 has been used for qualitative data management and analysis. This study identified 14 different consequences of which 10 are more critical and 4 are less critical.

Based on findings it can be concluded that downsizing has inversely affected attitudes and behaviors of all employees. More experienced employees are less afraid of downsizing but downsizing has disrupted the thoughts of employees with less experience because they think they will be the victim of downsizing soon Downsizing has distorted perceptions about work and employees are feeling less job security. That's why they are now less committed, less motivated, less satisfied and they are thinking to switch their jobs as soon as they get better job opportunity. Economic downfall and losses are major reasons of downsizing. It has also been found that downsizing has more impact on attitudes of employees in the present case.

\section{Recommendations and limitations}

Most of the respondents commented that hiring policy of the organization is not appropriate and organization has done excess hiring. So it is a suggestion for practitioners that hiring policy must be amended according to the circumstances. If the organization will continue to hire more staff then downsizing will become a major legal and union issue as well because it is illogical to hire additional staff and use of downsizing policy at the same time. Despite of downsizing practitioners must also try to adopt some approaches other than downsizing such as work sharing. It will be helpful in implementing friendly downsizing otherwise there will be huge resistance.

It is a limitation of the study that this is qualitative in nature. Sample size is just 12 respondents and non-probability convenience sampling technique has been used to select the sample. In future research may also be done quantitatively or by using mixed methods with larger sample size to enhance the validity of results.

\section{References}

[1] Bennett, A. 1991. Downsizing Doesn't Necessarily Bring an Upswing in Organizational Profitability. Wall Street Journal (June 6): Bl.

[2] Lublin, J. S. 1991. Executives Find Unemployment Takes a Heavier Toll the Second Time Around. Wall Street Journal (July 9): Bl.

[3] Baumohl, B. 1993. When Downsizing Becomes Dumb-sizing. Time (March 15): 55
[4] Pearlstein, S. 1994. Corporate cutbacks yet to Pay Off. The Washington Post (January 4): B6.

[5] Harrigan, K. R. 1980a. Strategies for declining businesses. Lexington, MA: Lexington Books. 1980b. Strategy Formulation in Declining Industries. Academy of Management Review 5: 599-604.

[6] Greenhalgh, L. and Z. Rosenblatt. 1984. Job Insecurity: Toward Conceptual Clarity. Academy of Management Review 9: 438-448.

[7] Perry, L. T. 1986. Least-Cost Alternatives to Layoffs in Declining Industries. Organizational Dynamics 14: 48-61. http://dx.doi.org/10.1016/0090-2616 (86)90043-4.

[8] Brockner, J. 1988. The Effects of Work Layoffs on Survivors: Research, Theory, and Practice. Research in Organizational Behavior 10: 213-255.

[9] Leana, C. R. and D. C. Feldman. 1992. Coping with Job Loss: How Individuals, Organizations, and Communities Respond to Layoffs. New York: Macmillan/Lexington.

[10]Cascio, W. F. (1998). Learning from outcomes: Financial experiences of 311 firms that have downsized. In M. K. Gowing, J. D. Kraft, \& J. C. Quick (Eds.), The new organization reality: Downsizing, restructuring, and revitalization (pp. 55-70). Washington, DC: American Psychologist Association.

[11]Hoerr, J. 1988. And the Wolf Finally Came: The Decline of the American Steel Industry. Pittsburgh: University of Pittsburgh Press.

[12]Cameron, K. S. 1994. Strategies for Successful Organizational Downsizing. Human Resource Management 33: 189-212. http://dx.doi.org/10.1002/hrm.3930330204.

[13]Feldman, D. C. and C. R. Leana. 1994. Better Practices in Managing Layoffs. Human Resource Management 33: 239-260. http://dx.doi.org/10.1002/hrm.3930330206.

[14] Schweiger, D. M., J. M. Ivancevich, and F. R. Power. 1987. Executive Actions for Managing Human Resources before and After Acquisitions. Academy of Management Executive 1: 127-138. http://dx.doi.org/10.5465/AME.1987.4275830.

[15]Cameron, K. S., S. Freeman and A. Mishra. 1991. Best Practices in White-Collar Downsizings: Managing Contradictions. Academy of Management Executive 5:57-73. http://dx.doi.org/10.5465/AME.1991.4274469.

[16]Greenhalgh, L. and T. D. Jick. 1989. Survivor Sense Making and Reactions to Organizational Decline: Effects of Individual Differences. Management Communication Quarterly 2: 305-327. http://dx.doi.org/10.1177/0893318989002003002.

[17]Freeman, J. and M. T. Hannan. 1975. Growth and Decline Processes in Organizations. American Sociological Review 40: 215-228. http://dx.doi.org/10.2307/2094346.

[18] Hambrick, D. C. and R. A. D'Aveni. 1988. Large Corporate Failures as Downward Spirals. Administrative Science Quarterly 33:1-23. http://dx.doi.org/10.2307/2392853.

[19]Kimberly, J. R. and R. H. Miles. 1980. The Organizational Life Cycle. San Francisco: Jossey-Bass.

[20]Clark, J., \& Koonce, R. (1995). Engaging organizational survivors. Training and Development, 49(8), 22-30.

[21]DeMeuse, K. P., Bergmann, T. J., \& Vanderheiden, P. A. (1997). Corporate downsizing: Separating myth from fact. Journal of Man$\begin{array}{lll}\text { agement } \quad \text { Inquiry, } & \text { 6(2), }\end{array}$ http://dx.doi.org/10.1177/105649269762010.

[22] Worrall, L., Cooper, C., \& Campbell, F. (2000). The impact of organizational change on the work experiences and perceptions of public sector managers. Personnel Review, 29(5), 613-636 http://dx.doi.org/10.1108/00483480010296429.

[23]Cook D. S. and G. R. Ferris. 1986. Strategic Human Resource Management and Firm Effectiveness in Industries Experiencing Decline. Human Resource Management 25: 441-458. http://dx.doi.org/10.1002/hrm.3930250308.

[24]Markham, S. E. and G. H. McKee. 1991. Declining Organizational Size and Increasing Unemployment Rates: Predicting Employee Absenteeism from Within- and Between-Plant Perspectives. Academy of Management Journal 34: 952-965. http://dx.doi.org/10.2307/256399.

[25]Mone, M. A. 1994. Relationships between Self-Concepts, Aspirations, Emotional Responses, and Intent to Leave a Downsizing Organization. Human Resource Management 33: 281-298. http://dx.doi.org/10.1002/hrm.3930330208.

[26]Yu, G. C., \& Park, J. S. (2003). The effect of downsizing on a firm's financial performance. Personnel Management, 27, 275-302

[27]Cameron, K. S., D. A. Whetten, and M. U. Kim. 1987. Organizational Dysfunctions of Decline. Academy of Management Journal 30: 126138. http://dx.doi.org/10.2307/255899.

[28]Schuler, R. S. and S. E. Jackson. 1987. Organizational Strategy and Organizational Level as Determinants of Human Resource Management Practices. Human Resource Planning 10: 125-141. 
[29]Staw, B. M., L. E. Sandelands, and J. E. Dutton. 1981. Threat-Rigidity Effects in Organizational Behavior: A Multilevel Analysis. Administrative Science $\quad$ Quarterly 26: 501-524. http://dx.doi.org/10.2307/2392337.

[30]Al-Kazemi, A., \& Zajac, G. (1998). The self-managed team and tori theory. International Journal of Commerce and Management, 8(1), 70-87 http://dx.doi.org/10.1108/eb047364.

[31]Lam, H., \& Reshef, Y. (1999). Are quality improvement and downsizing compatible? A human resources perspective. Relations Industrielles, 54(4), 727-744. http://dx.doi.org/10.7202/051270ar.

[32] Armstrong-Stassen, M. (1997). Organizational downsizing and quality management programs: Can they coexist? Discussion paper. Boston, MA: Academy of Management

[33]Sverke, M., Hellgren, J., \& Naswell, K. (2002). No security: A metaanalysis and review of job insecurity and its consequences.Journal of Occupational Health Psychology, 7(3), 242-264 July. http://dx.doi.org/10.1037/1076-8998.7.3.242.

[34]Williams, S. M. (2004). Downsizing - Intellectual capital performance anorexia or enhancement? The Learning Organization, 11(4/5), 368-379. http://dx.doi.org/10.1108/09696470410538260.

[35] Sronce, R., \& McKinley, W. (2006). Perceptions of organizational downsizing. Journal of Leadership and Organizational Studies, 12(4), 89-108. http://dx.doi.org/10.1177/107179190601200406.

[36]Armstrong-Stassen, M., Reavley, M., \& Ghanam, D. (2005). Organizational downsizing and its perceived impact on quality management practices. The International Journal of Quality and Reliability Man$\begin{array}{ll}\text { agement, } & \text { 22(8/9), }\end{array}$ http://dx.doi.org/10.1108/02656710510625220.

[37]Saif, N., Rehman, K., Rehman, S., Khan, M.S., Rehman, Z. \& Khan, B. (2013), the impact of downsizing on the socio-economic condition on affected employees. The case of Pakistan International Airline. International Journal of Academic Research in Accounting, Finance and Management Sciences, 3(1), 68-79 January.

[38] Yin, R. (2003). Case Study Research (3rd ed.). London, England: Sage Publications.

[39]Ozkan, Betul C. Using NVivo to Analyze Qualitative Classroom Data on Constructivist Learning Environments. The Qualitative Report, 2004: 589-603.

[40]Lodhi, R.N. \& Malik, R.K. (2013), Impact of electricity shortage on daily routines: A case study of Pakistan. Energy \& Environment, 24 (5), 701-709. http://dx.doi.org/10.1260/0958-305X.24.5.701. 